\title{
Why obese women feel better about their "big" condition when they are pregnant: A qualitative study performed in Sweden
}

\author{
Annsofie Adolfsson", Janne Finnerup Andresen, Kristin Brattstrom Edgren
}

School of Health and Medical Sciences, Örebro University, Örebro, Sweden

Email: ${ }^{*}$ annsofie.adolflsson@,oru.se

Received 12 July 2013; revised 10 August 2013; accepted 17 August 2013

Copyright (C) 2013 Annsofie Adolfsson et al. This is an open access article distributed under the Creative Commons Attribution License, which permits unrestricted use, distribution, and reproduction in any medium, provided the original work is properly cited.

\begin{abstract}
Overweight and obesity as measured by the body mass index (BMI) is an increasing problem worldwide according to the World Health Organization (WHO) [1]. Women having a body mass index greater than or equal to $30 \mathrm{~kg} / \mathrm{m}^{2}$ are considered to be obese and they run a greater risk of complications when they are pregnant. Complications such as high blood pressure, gestational diabetes, risk of intrauterine fetal death and slower delivery when giving birth to the baby are risks that can affect the well being of the woman and the child. According to the study on the women, the midwife's most important role when meeting with the pregnant obese woman is to inform them about potential risks during pregnancy. The midwife must withhold judgment. For many women living with obesity means that they are not seen as the person they actually are. Obese women feel that they do not conform to the societal ideal of an attractive woman because of their size and because of other people's prejudices regarding their obesity. When an obese woman becomes pregnant they may feel more comfortable with their standing in society because there is a happy explanation for the size of their abdomen. They experience that they are happy and proud about their stomach and this gives them a sense of relief and belonging.
\end{abstract}

Keywords: Obesity; Pregnancy; Support; Midwife

\section{INTRODUCTION}

Obesity is a growing problem worldwide and is considered by the World Health Organization (WHO) as a national disease. The increase of obesity is due to changing lifestyles and also heredity [2-4]. Being pregnant and

"Corresponding author. having a body mass index greater than or equal to 30 $\mathrm{kg} / \mathrm{m}^{2}$ involves risks for both the woman and the unborn child [5-7].

Complications for obese women can include a greater risk for gestational diabetes [8], prolonged labor $[4,8]$ and an increased risk of needing a caesarean section [5, 7-10]. The baby also has an increased risk for malformations and makrosomi [7,11].

Pregnant obese women present complications for the midwife as well, as it is more difficult to judge the woman on maternity care and actual childbirth $[7,12,13]$. These pregnancies are generally classified as a risk pregnancy [2]. The support from the midwife has a definite influence on how women feel about their pregnancy and prospective childbirth. There are requirements of the midwife in the hospital that they put their own values and attitudes aside [14,15]. There has been much research done about the medical risks for the woman and the child [16]. There also has been research done about how the midwife experiences meeting with the pregnant obese woman [17]. Midwives are aware of the delicate nature of the conversation when discussing obesity and the consequences it may have for the woman during pregnancy $[16,18]$. This conversation may make them feel apprehensive about stating the facts. This study intends to contribute more knowledge about how pregnant obese women feel about meeting with the midwife and how they think and feel about their pregnancy.

\section{AIM}

The aim of the study was to describe obese women's experiences of being pregnant and how they feel about their encounter with the midwife in maternity care.

\section{METHOD}

In order to get a better understanding of what it is like to 
be pregnant and obese we elected to do a qualitative interview study with an inductive approach.

The study was conducted with pregnant women enrolled in prenatal care in an area of Västra Götaland. This area comprised of a total of 15 municipalities that are mostly made up of small towns and rural areas. Midwives working in this jurisdiction have established guidelines to work from when it comes to working with pregnant obese women. The guidelines consist of five main points as follows:

- Information about the establishment of goals

- Medical risks for obese pregnant women

- Proposed questions for the women at the initial visit

- Outline for the care during the pregnancy

- Follow up visit eight weeks after delivery

The selection criteria for the study was that the women should reside in a specific area of Västra Götaland and they should have a variety of ages, level of education, places of residence (rural or urban), different backgrounds, different socio-economic conditions and they should have a variety in the stages of their pregnancy. The selection criteria also included that the women are obese and pregnantat the time of enrollment and they should speak Swedish. Invitations to the study would be made at the time of enrollment in the clinic and extended by midwives at three selected antenatal clinics in this specific area where the research was significant.

Permission was obtained to interview the pregnant women enrolled in prenatal care clinics in this area by contacting operation managers in the area. An information letter was distributed to business managers who then forwarded the information to the midwives at the Maternity Health Care Center (MVC). The midwives then presented the study to the target audience of the obese pregnant women and they in turn contacted the midwife if they were interested in participating. The interviewees had to decide upon a place and time for the interview from three specific proposals: the antenatal clinic (MVC), the home of the woman or at the university. Information about the study was distributed by midwives at the MVC.

\subsection{Data Collection}

Before the interview began the interviewees were informed about the procedure for the interview and what the roles of the authors were as interviewer and as observer. During the interviews one author was active and asked questions while the other author looked on as an observer who focused on latent content and posed any questions that they felt were necessary to develop the data. The data was collected over a span of five interviews in which the authors switched roles from interviewer to observer.

Each of the participants was required to read the written information distributed by the midwife at the MVC when they registered for the study. They were required to sign a written consent form to participate in the study. The interview structure was designed with an interview guide that was made up of the following unstructured questions:

Can you tell us a little bit about yourself and who you are?

Can you tell us about any difficulties that you had in becoming pregnant?

How do you feel about being pregnant?

How have your contacts been with the midwife during your pregnancy?

How would you like to be treated by the midwife at the MVC?

The women were encouraged to speak freely when they answered the questions and they were given sufficient time to reflect upon their answers [19]. Three of the interviews were conducted at the MVC, one was conducted at each home of the women and one was conducted at the university. The interviews lasted between 28 and 40 minutes in duration and were conducted in a peaceful environment without being interrupted by other people or distractions. The authors discussed each interview together and documented their feelings about it. Each interview was recorded in its entirety and then transcribed verbatim into a text by the observer of the interview.

\subsection{Data Analysis}

The data was analyzed using qualitative content analysis according to Graneheim and Lundman [20]. The transcripts of the interviews were read through several times by the authors to extract the entire meaning of the data with respect to the aim. Then the content was discussed among the authors in order to extract any underlying meaning in the interviews. Meaning bearing units were identified from the text and they consisted of words and quotes that were considered to be relevant to the purpose and aim of the study. It was important to express the meaning bearing units as full sentences so that the integrity of their experiences was maintained. Then the meaning bearing units were condensed in order to make the text shorter and more manageable while preserving the message from the text. The condensed meaning bearing units were given different color codes to distinguish between the similarities and the differences in the interviews. According to Coffey and Atkinson [21] the created codes correspond to the context of the meaning bearing units. The codes enable the researchers to reflect on their data for additional insight [21]. The hidden messages make up the latent content which is identified and made visible through the creation of the theme [20]. The analysis process of the interview text was interpreted in its context and from the interviewees' point of view [22] 
(see Table 1).

According to Krippendorf [23], the transcripts are subject to the interpretation of the reader. In relation to qualitative content analysis this means that according to Krippendorf [23] the text does not have a specific meaning and that multiple interpretations are possible. Even though the possibility exists that the text can be interpreted differently the different interpretations can be considered valid. Table 1 shows an example of how the content analysis was made.

\subsection{Ethical Aspects}

In studies that have been made about people, privacy and dignity must be taken into account in order that they are not violated. According to the Declaration of Helsinki [24], participants should be well informed about the study's purpose and procedures. Participation should be

Table 1. Summary of the results with one theme divided into five categories and eighteen subcategories.

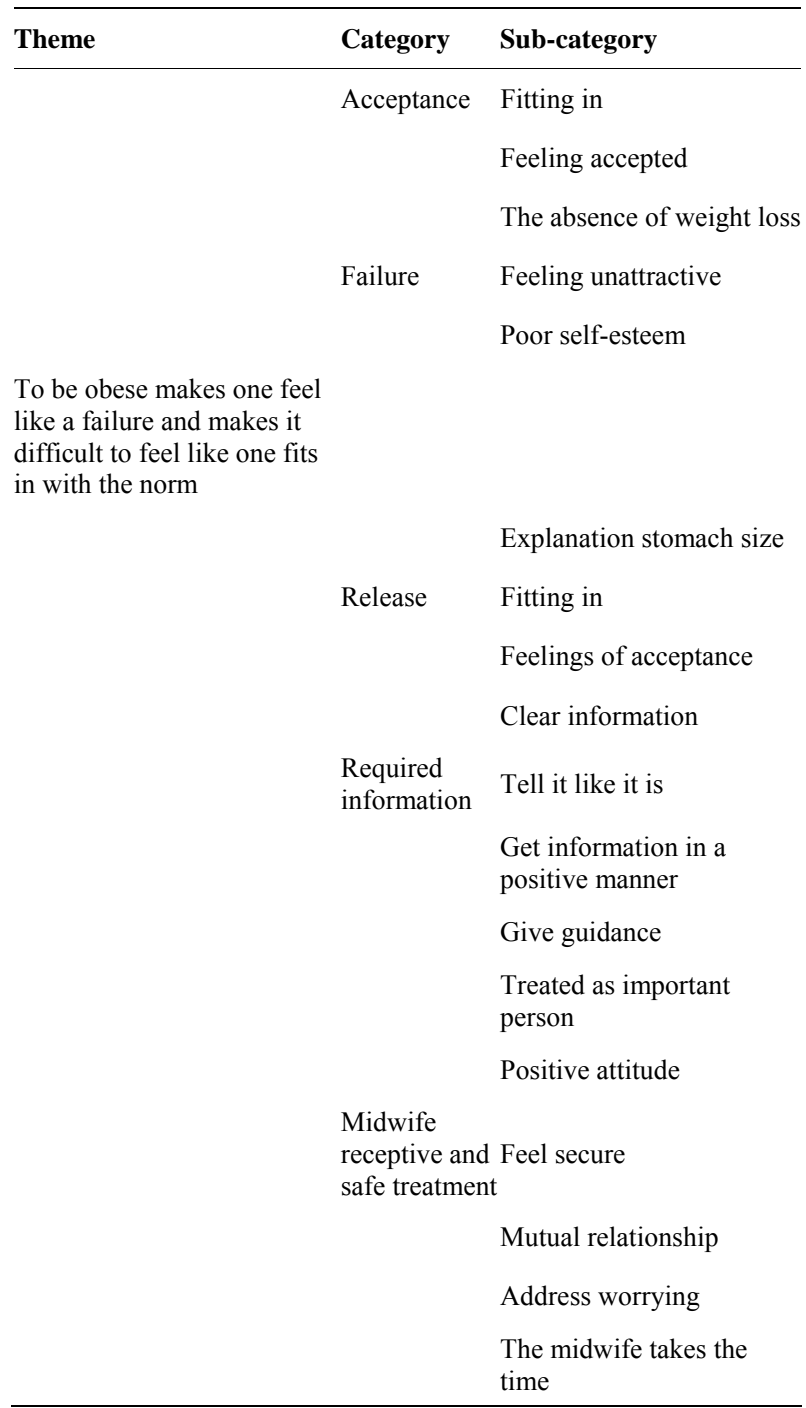

voluntary and the participants should have given a consent form and they should be in formed that they may cancel their participation at any time during the study [24].

\section{RESULTS}

The findings of this study describe how five obese pregnant women experience their pregnancy and their meeting with the midwife in MVC. The theme that evolved from the data analysis was that women who are obesely overweight feel like failures and they do not feel like they fit in with society and societal norms. The theme and the five categories that evolved in the study are presented below in Table 2.

\subsection{Acceptance}

To take part in a study about obese women's experiences of being pregnant did not feel comfortable for all of the women. They had a difficult time actually seeing themselves as obese and this made it difficult to feel as if they fit into the study with this purpose. The invitation may come as a surprise to an obese woman who has not accepted the fact that she is obese.

When the midwife called yesterday with the invitation it felt terrible...

The study showed that some of the women did not have a realistic image of themselves.

Is till feel pretty... pretty normal if I don't see my reflection...

Table 2. The table shows examples of how the authors have developed the content analysis according Graneheim and Lund man's (2004) model.

\begin{tabular}{|c|c|c|c|}
\hline $\begin{array}{l}\text { Meaning } \\
\text { bearing unit }\end{array}$ & $\begin{array}{l}\text { Condensed } \\
\text { meaning } \\
\text { bearing units }\end{array}$ & Code & Subcategory Category \\
\hline $\begin{array}{l}\text { I have thoughts } \\
\text { that are there all } \\
\text { the time...how } \\
\text { to fit into the } \\
\text { template } \\
\text { somehow }\end{array}$ & $\begin{array}{l}\text { Thoughts of } \\
\text { fitting into the } \\
\text { template } \\
\text { non-stop }\end{array}$ & $\begin{array}{l}\text { Fitting } \\
\text { the } \\
\text { template }\end{array}$ & Fitting \\
\hline $\begin{array}{l}\text { I still feel pretty } \\
\text { normal if I do } \\
\text { not see myself }\end{array}$ & $\begin{array}{l}\text { I feel normal } \\
\text { if I do not } \\
\text { see myself }\end{array}$ & $\begin{array}{l}\text { Feeling } \\
\text { normal }\end{array}$ & \\
\hline $\begin{array}{l}\text { People look at } \\
\text { me funny and } \\
\text { comment that I } \\
\text { eat too much, } \\
\text { exercise too } \\
\text { little because I } \\
\text { am lazy }\end{array}$ & $\begin{array}{l}\text { Being exposed } \\
\text { funny looks } \\
\text { and rude } \\
\text { comments }\end{array}$ & $\begin{array}{l}\text { Feels } \\
\text { stared at }\end{array}$ & $\begin{array}{l}\text { Feeling } \\
\text { accepted }\end{array}$ \\
\hline $\begin{array}{l}\text { I want to be } \\
\text { seen as an } \\
\text { individual and } \\
\text { not labeled as a } \\
\text { fat person }\end{array}$ & $\begin{array}{l}\text { Seen as a } \\
\text { person and not } \\
\text { as a fat person }\end{array}$ & $\begin{array}{l}\text { Seen as } \\
\text { a person }\end{array}$ & \\
\hline
\end{tabular}


The women also revealed in the interview their experience of living with obesity and their feelings of having difficulty fitting in. They felt that they were not normal. All the women expressed that they wanted to be seen as a normal person when meeting other people. They wanted to be seen as an individual and not as an obese person. The study revealed that most of the women were sensitive to how people perceive them and they had the feeling that people judge them by how overweight they are. The women felt that people gave them funny looks and they endured comments about their eating habits, their lack of activity and their lack of character and discipline. The combination of funny looks and derogatory comments let them know in advance that people were judging them by their size. From the women's perspective it was because of preconceptions about people with obesity and the prejudices of others. The women in general felt a bias that thin people are more attractive because they are more energetic and consequently they are worth more as people. The study showed that some of the women held the belief that thin people live better and easier lives. Some of the women were of the opinion that weight loss does not automatically lead to a happier life. Others felt that their size did not matter to other people.

Some women did not put their obesity as a high priority as to how they accepted themselves. They were able to manage any negative feelings they may have regarding their condition or appearance. One woman expressed it as follows.

Well of course it can be a sensitive matter...but realistically I weigh what I weigh and I look like I do...it's just the way it is.

The study revealed that some of the women had experienced eating disorders during their adolescence and they felt it was difficult to get a handle on their weight. In adulthood they had more or less accepted the fact that they were overweight and it was just something they had to live with. This is partly due to a family history of obesity too. Some of the women had worked out some of their issues about their size with the help of counseling. They came to realize and accept themselves for the person that they are.

\subsection{Failure}

Living with obesity gave women a sense of being a failure. The women felt that during their childhood and adolescence that they were bigger than their classmates. This led them to attempt to lose weight and often it was without success which further contributed to their sense of being a failure. The sense of failure is emotionally painful to them. Further contributing to their emotional pain were feelings that they were not attractive which in turn gave them a sense that they were not enjoying them- selves in their condition. As a result they experience a loss of confidence and self-esteem.

Both my partner and I were overweight before, but he has successfully lost a good bit of weight and I have stayed the same...this made me feel even less attractive.

\subsection{Release}

The study revealed that the women went into their pregnancy with low self-esteem and a sense of not being satisfied with themselves because of weight issues. When their pregnancies became their reality however their feelings began to change and they felt an increase in their self-esteem. One woman expressed that it was liberating to be pregnant and she was able to be herself without worrying what others thought or were thinking. The women had a better sense of fitting in as now there was another explanation for their size. The fact that they were pregnant gave them a feeling that their being "big" was more legitimate. It was still difficult for the obese pregnant women to not be recognized as pregnant as early as thinner women were recognized to be pregnant. All of the women in the study felt that it was more rewarding if others recognized they were pregnant without them having to bring it up first.

But it is good to know that you want to show that you are pregnant in the beginning...it is a little difficult when you know that it is growing and everything and nobody else sees it.

But I don't want to wait almost the entire pregnancy until they will notice that I'm pregnant...so it may be that Ibring it up myself....this is a little tiresome.

All of the women felt that the baby in the stomach was a welcomed experience regardless of whether or not it was planned. Some women felt that they were not attractive to their partners because of their obese condition and this may contribute to reducing their interest in having sex.

These conditions are obviously going to have a negative effect on the reproductive process. Obese women who have had a miscarriage had a more difficult time getting pregnant again. When these women had difficulty getting pregnant they were tested for infertility and received advice that they should lose weight. They were surprised when they got pregnant even if they had only a relatively small weight loss. All of the women felt that it was very satisfying to know that their bodies were functioning properly when they got pregnant and that made them very proud of their growing belly.

This meant that I...by being pregnant...that I could actually be proud of my belly for a change. Otherwise I would not be.

All of the women experienced their pregnancies positively. They described being pregnant as a special feeling and that if felt feminine, powerful, wonderful, exciting, 
beautiful and cool. One woman said that it felt good because her stomach became firmer and another woman said that the stomach was one that one could be proud of instead of being self-conscious about.

When you are overweight you hide it...it shouldn't be seen. But when pregnant you wait...to grow so that you can show it off and feel good about it and such things.

\subsection{Required Information}

The study revealed that some of the women actively sought information regarding pregnancy in books and on the internet. The women who were seeking information differed in their perceptions about the complications and some of them were more aware of the possible complications compared to others. For example, the women who had previously given birth tended to be more aware of the complications and risks during pregnancy and childbirth than those that had not. The study further showed that some of the women had specific knowledge of complications of obese pregnant woman but it was as if it did not pertain to them. Some of the women felt that they were fully aware of everything and that the midwife did not contribute anything in the way of new knowledge. It was a common feeling among the women that they were doing well despite any risks for complications in pregnancy.

I am not really certain how dangerously overweight I am...in fact I feel really good. But at the same time it doesn't feel life threatening. At least right now...in any case.

The study also showed that some of the women were perplexed that they didn't have complications given the risks that exist with obese women who are pregnant. These are risks that include such things as high blood pressure and having difficulty in becoming pregnant.

Of all of the complications one can have when you're big and pregnant...so far I don't think that I have any... hypertension and whatever it may be...right now there isn't anything wrong with me.

All of the women in the study felt some concern that something could possibly go wrong during their pregnancy and they had concerns regarding the upcoming delivery and birth. The women who had delivered babies previously had thoughts and concerns based on their earlier experiences. These concerns included things such as the length of their labor, the ability to get an epidural, vaginal tearing, along with concerns that the infant would not do well immediately after delivery. Those with no previous experience of childbirth were wondering how it would feel when the water breaks and how it would actually feel to give birth. The study demonstrated that pregnant and obese women felt that it was important for the midwife to be competent and skilled in order for her to provide relevant information and advice. Most of the women also felt that it was important that the infor- mation would be straight forward and honest and no information would be withheld from them.

It's not going to be something silly...I just want to get it...you know, give it to me like it is. It's not like "what did you do yesterday?"...focus on the facts and give it to me straight.

The women were pretty much aware of their situation with the pregnancy and obesity complications but they felt that too much should not be made of the complications. It would be better if the midwife presented them with their predicament as a fairly natural process without embellishing or exaggerating their problems. The women want guidance from their midwife to help them through their pregnancy and this includes getting the right information about what was best for their child in the womb and what was best for themselves. They wanted someone that was experienced and someone they felt confident in. Someone that was competent and able to provide them with the answers to questions that they had.

...They have a lot of experience and they can make the right judgment at the right time...

Midwife is receptive and provides secure treatment.

The obese pregnant women felt that it was important that the midwife had an open and receptive attitude about their circumstances and that they felt secure with her from the start. Most of the women experienced the visits to the midwife as warm and secure and that they were pleasant meetings where they were relieved of their concerns. The women expressed that they wanted the midwife to feel that they were the top priority when they were meeting with her.

...When it's my turn for my appointment it should be all about me and the focus should be on me and my baby. I hope that we are not interrupted and even prefer that she have her phone calls forwarded...

...I want to be treated as if it's important to her that I'm here...and it is my hope that she thinks it's interesting to have me as her patient while I am there.

Several women expressed that it was important to feel comfortable to be themselves when visiting their midwife and that she made them feel accepted as the person that they were. All women stated that they wanted to be treated with respect as an individual and not as an obese person. They certainly did not want to be judged because of their size.

...she gave me the feeling...there was no judgmental look...there wasn't a comment that could have been interpreted as somehow I had failed...but she is accommodating from the start as well...In ever felt as if I had done something wrong.

Being seen and being listened to felt important to all of the women. The women felt that the support from the midwife was very important during the pregnancy and they also wanted the possibility to talk about other things 
other than just pregnancy. They strongly desired a mutual relationship that went both ways in order to feel confidence in the midwife and vice versa. This gave them the confidence to open up and express themselves. This gave them the security that they needed that their midwife was going to be there for them if things got difficult or if the women felt that they needed assistance in any other matters that were important to them. It was important for the women to feel that they had a trusting relationship with their midwife.

...So when I called with a problem I got a good response right away...it was possible to see her if needed... my worries were addressed and were not just swept under the rug.

These women felt that it was important to have the same midwife throughout their maternity care to build a trusting relationship. It felt safer with the continuity of having the same midwife and it gave the women and the midwife the opportunity to know one another in order to communicate most effectively with each other. The women appreciated it when the midwife greeted them in the waiting room with recognition as if they were engaged with each other on a level that made them feel welcomed.

For all of the women it was important that the midwife was confident in herself and in her experience and her knowledge. They wanted to see their midwife as a secure and stable person who was there for them. They wanted the midwife to be sympathetic and accommodating but also they wanted to be treated with some warmth.

...it give me the feeling that I am received with open and warm arms...her reception makes me feel welcome... as if everything is going to be alright and nothing will go wrong...she makes me feel that she will be sympathetic all the time...this is really important to me.

All of the women enjoyed their visits with the midwife. Some had changed midwives when they felt that the midwife was not compatible with their own expectations about how a caregiver should be. One woman might find a midwife to be stiff and uncomfortable and another woman might find the same midwife to be confident and knowledgeable. Sometimes it just boiled down to chem.istry between two people. Generally though, the women were satisfied with the relationships with their midwives. One woman said that she felt that her midwife liked her and another woman said that her midwife was the best in the world.

I felt that I could feel safe...In ever feel any stress about coming here...but I feel safe when I come here and trust her...she helps me through something that may be difficult just like I knew that she would.

Most of the women said that it felt good if their relationship somewhat transcended the role of caregiver and patient. They appreciated the opportunity to engage in a bit of small talk with their midwife and it made them feel at ease and comfortable. This helped to create a bond of engagement with their midwife. Some women however said that they were not interested in small talk but only wanted to go their appointment and take care of pregnancy business. These women expressed that they did not care to have too much of a personal relationship with their midwife.

When the midwife attempted to inject humor into their approach to maternal health it was perceived positively by some of the women, but not always. The women who experienced humor negatively may have felt that the midwife was a decent person but the attempt to use humor may have been slightly unprofessional and not suitable for the situation. Others thought that it was humorous if the midwife made light of the fact that they had gained weight and laughed it off. In this way it made the women feel comfortable with their obesity if the midwife was tactful and sensitive with her humor. It is a very sensitive issue with obese women and the midwife must be careful not to offend them or hurt their feelings. But by treating the subject lightly and with gentle humor it helped the women to not be so focused on the number of pounds that they had gained.

\section{DISCUSSION}

The study results demonstrate that pregnant women who are obese feel that they do not conform with society's ideals for pregnant women because of their obesity. The women experience a sense of failure that contributes to diminished confidence and a general lack of self-esteem. However during their pregnancy the women are provided with a sense of relief because the pregnancy provides them with a natural explanation for the size of their stomach. Obese women often go into their pregnancy with low self-esteem and a fear of judgmental comments. The midwife has the responsibility to treat and manage the women's maternal health care by establishing a relationship of mutual trust and respect. The midwife enables the women to have self-confidence if they are perceived as being non-judgmental and respectful.

The study revealed that some of the women actually perceived themselves as having a normal weight. According to the World Health Organization's [25] classification of obesity, individuals that have a Body Mass Index greater than or equal to $30 \mathrm{~kg} / \mathrm{m}^{2}$ are considered to be obese. It also qualifies them as having a disease according to the Swedish Council of Health Technology Assessment in 2007. This definition is now used in the health care system including the prenatal care in Sweden. As the number of cases of obesity increase it becomes increasingly acceptable to be obese as it becomes more common in the community. The boundaries of what are considered to be normal weight, or overweight and obese 
shifts which is something that emerged from [3].

These shifting boundaries can create confusion and anxiety for obese pregnant woman that have registered with the MVC and this is something that the midwife should keep in mind when meeting these women. In the course of this study we have reflected upon the use of the words overweight and obesity. In everyday speech the word obesity has a more negative connotation and it is difficult to use this word when talking to these women and referring to their condition according to Heslehurst et al. [13]. The word overweight seems to have a more neutral connotation and is less emotionally charged for the women.

To conform to the societal ideal of body size is a recurring factor in the interviews with the five women who were obese and pregnant. Since obesity is so visible externally and not easily disguised, the women in this study often experience prejudice and ignorance from other people regarding their condition. Other people's subtle reactions about their condition can give the women a sense of not fitting in and this can lead to a loss of confidence and self-esteem which is consistent with the study of Heslehurst et al. [13]. The study of Nyman et al. [18] describes how it feels to live with obesity and how it feels to be constantly aware of the condition of one's body. It is very important that the midwife in her encounter with obese pregnant women takes the time to form a strategy with which approach to use with each individual woman in order to give her the support she needs according to the study by Hall and Wigert [26]. This can be a balancing act because women are different as individuals with different experiences and backgrounds therefore the strategy must be well thought out.

When it was confirmed that the women were pregnant the obese women were finally able to feel somewhat proud of their stomach. The pregnancy gave them an acceptable explanation for the size of their stomach. This result is consistent with previous studies including Fox and Yamaguchi [27] and Smith and Lavender [7]. The women in this study and in Furber and in the McGowan [12] study expressed disappointment when they did not exhibit outwardly perceptible signs that they were pregnant early on in their pregnancies.

This study confirmed that the obese pregnant women were satisfied with the attitudes of the midwives' at the MVC when they were treated according to their individual needs. The midwives involved in the maternity healthcare from an area of the southwest of Sweden are working from a memo with regards to the care of obese pregnant women and thus can take further action if something deviates from the normal course of pregnancy. The authors of the study believe that this memo gives the midwives' an advantage when they meet with these wo- men because they have a plan of action for known risk factors and that same information was distributed to all of the pregnant women with an obese condition. This can give the midwife a basis for feeling secure when dealing with this particular group of women on a sensitive subject.

According to the ethical code in midwifery duties, it is the midwife's responsibility to try and give the women realistic expectations for childbirth [14]. The women in the study specifically requested this information. They expressed that they needed this information from the midwife and that it would be provided in a straight, honest and concise manner with their wellbeing and the wellbeing of their baby being the focus of the information $[7,12]$.

When the women in the study came to the Maternity Healthcare Center they expected total engagement with the midwife in order to feel important and confident according to Nyman et al. [18]. Berg [16] also emphasizes the importance of the midwife being both emotionally and physically present in their relationship with the women and that this is an integral part of caring. If the midwife shows respect and interest in the woman, this will encourage a minimization of discomfort and their meetings can feel more informal and relaxed [28].

When the midwife did not fulfill a obese pregnant woman's expectations the woman changed midwives'. The women felt that their relationship with their midwife depended more upon how the midwife related to them as a person than her skills as a midwife. An important determining factor in the relationship between the patient and her midwife is that of reciprocity. If the relationship is one that goes both ways it leads to trust and confidence in both parties according to Berg [28]. This is consistent with the midwife's ethical code that says that the approach should be based on mutual respect and trust [14].

The study further demonstrated that the women liked to discuss unrelated subjects other than their pregnancy but there were limitations as to how close they desired to become with the midwife. The small talk helped to break the ice when discussing the sensitive issues as they related to their pregnant and obese condition but it did not necessarily lead to a closer friendship according to Hall and Wigert [26].

When the midwife attempted to use a sense of humor in the course of their treatment of the women it may be responded to in different ways. Some of the women may experience it in a positive manner when the midwife tried to diminish the gravity and importance of the weight problem which in turn helped the women to feel respected for the person they were. However, the humor could also be perceived negatively as the midwife may give the impression that she was unfocused. The use of 
humor could provide a bit of relief to the woman by talking and laughing together according to Nyman et al. [18]. The use of humor with regards to their body size and weight issues could lead to a better sympathetic understanding while giving the women a sense of security and a sense of being respected. An open and honest atmosphere between the woman and the midwife can give them an opportunity to relax and lighten up in potentially nervous and awkward situations as they pertain to their physical condition.

\section{CONCLUSION}

The women in the study expressed that being pregnant could give them the feeling that they somehow conformed better to societal expectations with regard to their size than they did when they were not pregnant. It gives them a feeling that the size of their pregnant abdomen is justifiable which makes it more normal and more acceptable to themselves and to others. The relationship with the midwife emphasizes the importance that the women are seen as individuals and not as people with obesity. It is important that the midwife is not judgmental in their attitudes with the women and that she meets with them without admonishing them. At the same time the duty of the midwife dictates to her that she must be straight and honest in relation to the information about the physical condition of the women based on the wellbeing of the baby and the woman during the pregnancy. All of the women were very satisfied with their midwives and felt that their needs for advice and support were fulfilled in their treatment by the midwives at the MVC.

\section{SUGGESTIONS FOR CLINICAL APPLICATION}

The results of the study demonstrated that all of the women felt badly about being so overweight but some of them had learned to accept their overweight condition and to live with it without being overly distressed by it. Given the woman's health and the future health of their children are at stake, it is important that the women who want to lose weight get the necessary support and help deal with their condition. Therefore it is important that the midwife fulfills the women's need for information and that she receives the help and support she needs to lose weight before and after pregnancy.

\section{SUGGESTIONS FOR FURTHER RESEARCH}

It would be of interest to research the effects of discussion groups of pregnant women on their issues concerning their health and that of their babies. We can conclude this based upon this target group of women that are obesely overweight based on the guidelines for the treatment of these overweight pregnant women in Sweden.

\section{REFERENCES}

[1] WHO (2003) World Health Organization definition of health. http://www.who.int/about/definition/en/print.html

[2] Lim, C. and Cheng, N. (2011) Obesity and reproduction. Journal of the Australian Traditional Medicine Society, 17, 143-145.

[3] Schmied, V.A., Duff, M., Dahlen, H.G., Mills, A.E. and Kolt, G.S. (2011) "Not waving but drowning": A study of the experiences and concerns of midwives and other health professionals caring for obese childbearing women. Midwifery, 27, 424-430. doi:10.1016/j.midw.2010.02.010

[4] Smith, S.A., Hulsey, T. and Goodnight, W. (2008) Effects of obesity on pregnancy. Journal of Obstetric, Gynecologic, \& Neonatal Nursing, 37, 176-184. doi:10.1111/j.1552-6909.2008.00222.x

[5] Ovesen, P., Rasmussen, S. and Kesmodel, U. (2011) Effect of pregnancy maternal overweight and obesity on pregnancy outcome. Obstetrics \& Gynecology, 118, 305312. doi:10.1097/AOG.0b013e3182245d49

[6] Phillips, F. (2012) Obesity in pregnancy. Practice Nurse, 6, 32-37.

[7] Smith, D. \& Lavender, T. (2011) The maternity experience for women with a body mass index $\geq 30 \mathrm{~kg} / \mathrm{m}^{2}$ : A meta-synthesis. An International Journal of Obstetrics and Gynaecology, 118, 779-789. doi:10.1111/j.1471-0528.2011.02924.x

[8] Hanson, U. (2008) Diabeticand pregnancy. In: Hagberg, B.H., Maršál, K. and Westgren, M., Eds., Obstetrik, Studentlitteratur, Lund, 379-392.

[9] Smith, G., Shah, I., Pell, J., Crossley, J. and Dobbie, R. (2007) Maternal obesity in early pregnancy and risk of spontaneous and elective preterm deliveries: A retrospective cohort study. American Journal of Public Health, 97, 157-162. doi:10.2105/AJPH.2005.074294

[10] Hildingsson, I. and Thomas, J. (2012) Perinatal outcomes and satisfaction with care in women with high body mass index. Journal of Midwifery \& Women's Health, 57, 336344. doi:10.1111/j.1542-2011.2011.00141.x

[11] Heude, B., Thiébaugeorges, O., Goua, V., Forhan, A., Kaminski, M., Foliguet, B., Schweitzer, M., Magnin, G. and Charles, M.A. (2012) Pre-pregnancy body mass index and weight gain during pregnancy. Relations with gestational diabetes and hypertension, and birth outcomes. Maternal Child Health Journal, 16, 335-363. doi:10.1007/s10995-011-0741-9

[12] Furber, C.M. and McGowan, L. (2011) A qualitative study of experiences of women who are obese and pregnant in the UK. Midwifery, 27, 437-444. doi:10.1016/j.midw.2010.04.001

[13] Heslehurst, N., Moore, H., Rankin, J., Ells, L.J., Wilkinson, J.R. and Summberbell, C.D. (2011) How can mater- 
nity services be developed to effectively address maternal obesity? A qualitative study. Midwifery, 27, 170-177. doi:10.1016/j.midw.2010.01.007

[14] Association of Midwives (2012) En professionell sammanslutning. http://www.barnmorskeforbundet.se

[15] Social Board (2006) Competence description for registered midwife. National Board, Stockholm. http://www.socialstyrelsen.se/Lists/Artikelkatalog/Attach ments/9431/2006-105-1 20061051.pdf

[16] Berg, M. (2005) A midwifery model of care for childbearing women at high risk: Genuine caring in caring for the genuine. The Journal of Perinatal Education, 14, 921.

[17] Folope, V., Chapelle, C., Grigioni, S., Coëffier, M. and Déchelotte, P. (2012) Impact of eating disorders and psychological distress on the quality of life of obese people. Nutrition, 28, 7-13. doi:10.1016/j.nut.2011.12.005

[18] Nyman, V., Prebensen, Å. and Flensner, G. (2010) Obese women's experiences of encounters with midwives and physicians during pregnancy and childbirth. Midwifery, 26, 424-429. doi:10.1016/j.midw.2008.10.008

[19] Kvale, S. and Brinkman, S. (2009) The qulitative research interview. Studentlitteratur, Lund.

[20] Graneheim, U.H. and Lundman, B. (2004) Qualitative content analysis in nursing research: Concepts, procedures and measures to achieve trustworthiness. Nurse Education Today, 24, 105-112. doi:10.1016/j.nedt.2003.10.001
[21] Coffey, A. and Atkinson, P. (1996) Making sense of qualitative data. Complementary research strategies. Sage Publications Inc., Thousand Oaks, London, New Delhi.

[22] Granskär, M. and Höglund-Nielsen, B. (2008) Applied qualitative research in Health and caring sciences. Studentlitteratur, Lund.

[23] Krippendorff, K. (2004) Content analysis. An introduction to its methodology. Sage Publications, Inc., Newbury Park, London, New Delhi.

[24] Codex (2012) Rules and guidelines to research. http://www.codex.vr.se/

[25] World Health Organization (2012) Fact file. 10 facts on obesity. http://www.who.int/features/factfiles/obesity/facts/en/

[26] Hall, E. and Wigert, H. (2010) Familjeinriktad neonatalvård. In: Berg, M. and Lundgren, I., Eds., To Support and Supporting and Strengthening, Nourishing Childbirth, Studentlitteratur, Lund, 191-201.

[27] Fox, P. and Yamaguchi, C. (1997) Body images change in pregnancy: A comparison of normal weight and overweight primigravidas. Birth, 24, 35-39. doi:10.1111/j.1523-536X.1997.tb00334.x

[28] Berg, M. (2010) Caring at childbearingwithhigh risk. In: Berg, M. and Lundgren, I., Eds., To Support and Supporting and Strengthening, Nourishing Childbirth, Studentlitteratur, Lund, 145-168. 